\title{
Occurrence of prostasome-like membrane vesicles in equine seminal plasma
}

\author{
A. Minelli ${ }^{1}$, M. Moroni ${ }^{1}$, E. Martínez ${ }^{2}$, I. Mezzasoma ${ }^{1}$ and G. Ronquist ${ }^{3}$ \\ ${ }^{1}$ Dipartimento di Biologia Cellulare e Molecolare, Via del Giochetto, Università di Perugia, 06123 Perugia, Italy; \\ ${ }^{2}$ Facultad de Farmacia, Universidad Complutense de Madrid, Madrid, Spain; \\ and ${ }^{3}$ Department of Clinical Chemistry, University Hospital, SE - 75185 Uppsala, Sweden
}

\begin{abstract}
Equine seminal plasma was shown to contain membrane vesicles that are similar to the well characterized prostasomes in human seminal plasma. Determination of nucleoside and nucleotide concentrations of these particles have shown that ATP, ADP and adenosine are the main components of the nucleotidic pool. 5' nucleotidase, endopeptidase and dipeptidyl peptidase IV activities have been found on the surface of the particles. The interaction between these prostasome-like vesicles and spermatozoa was demonstrated by electron micrograph scans which revealed the steps of a fusionlike process leading to mixing of the membranes. In addition, endopeptidase activity, a marker enzyme of these seminal vesicles that is normally absent from equine spermatozoa, was shown to be acquired by these cells after interaction with the vesicles. The addition of these vesicles to equine spermatozoa resulted in the modification of adenylate catabolism. Therefore, a role in stabilizing the energy charge of the spermatozoa thus allowing longer viability is proposed for these organelles.
\end{abstract}

\section{Introduction}

Membrane vesicles have been identified in the seminal plasma of several mammals (Davis, 1973; Ronquist et al., 1978a,b; Breitbart and Rubinstein, 1982; Fornes et al., 1991). These vesicles are secreted from different accessory organs of the reproductive system and are named after the producing organ. Prostasomes were identified in human ejaculates (Ronquist et al., 1978a,b), vesiculosomes in bovine seminal plasma (Agrawal and Vanha-Pertulla, 1987), and membrane organelles of epididymal origin in rabbit, ram and rat ejaculates (Davis, 1973; Breitbart and Rubinstein, 1982; Fornes et al., 1991). These extracellular vesicles express different proteins and enzymes on their surfaces and are involved in several physiological roles, ranging from immunosuppressive activity to the enhancement of sperm cell motility (Lord et al., 1977; Stegmayr and Ronquist, 1982; Kelly, 1991). These vesicles also exert opposing effects in the fertilizing process: in rabbits fertilization is inhibited (Davis and Hungund, 1976), but in bulls and humans forward sperm motility is promoted and the acrosome reaction is induced (Agrawal and Vanha-Pertulla, 1987; Ronquist et al., 1990).

The present paper deals with the occurrence, isolation and characterization of these extracellular vesicles in equine seminal plasma. The occurrence of a fusion-like process between the vesicles and sperm cells might help to clarify their physiological role in the fertilizing capacity of equine spermatozoa.

\section{Materials and Methods}

Nucleosides, nucleotides and enzyme substrates were from Sigma Co., St Louis, MO. Sephadex G-200 was from Pharmacia Biotech, Uppsala, Sweden. HPLC columns (Sulpelcosil LC 18T) were from Supelco Inc., Bellefonte, PA. Bio Rad protein assay was from Bio-Rad Lab, GmbH. All other reagents were of the highest available quality.

\section{Semen samples and sperm cell preparations}

Equine semen was obtained using an artificial vagina from stallions (trotters of proven fertility, 4-8 years old) stabled at Allevamento Spineta Trotto SaS, Sarteano, Italy. Ejaculate samples were pooled and centrifuged $(800 \mathrm{~g}$ for $10 \mathrm{~min}$ at $22^{\circ} \mathrm{C}$ ) to harvest spermatozoa and the supernatant (S1) was used to prepare membrane vesicles. The pellet was suspended in $10 \mathrm{mmol}$ 4-morpholinepropanesulphonic acid (MOPS) $\mathrm{I}^{-1}$, pH 7.4, containing $120 \mathrm{mmol} \mathrm{NaCl}^{-1}, 5 \mathrm{mmol} \mathrm{KCl}^{-1}$ and 0.5 mmol dithiothreitol $\mathrm{l}^{-1}$, and was stored at $22^{\circ} \mathrm{C}$ for further analyses. The number of spermatozoa was determined and their intactness was assessed by eosin vital dye and by measurements of lactate dehydrogenase (LDH) (EC 3.1.1.27) activity (Keiding et al., 1974; Minelli et al, 1997a,b).

\section{Preparation of membrane vesicles}

The supernatant (S1), diluted (1:1 v/v) with $30 \mathrm{mmol}$ Tris $\mathrm{l}^{-1}$ and $130 \mathrm{mmol} \mathrm{NaCl} \mathrm{l}^{-1}, \mathrm{pH} 7.6$ (buffer A), was centrifuged at $1000 \mathrm{~g}$ for $20 \mathrm{~min}$ at $4^{\circ} \mathrm{C}$ to eliminate cell debris and 
residual spermatozoa. The new supernatant was then centrifuged at $105000 \mathrm{~g}$ for $120 \mathrm{~min}$ at the same temperature. The pellet containing vesicles and amorphous material was suspended in buffer A up to $1.0-1.5 \mathrm{mg}$ protein $\mathrm{ml}^{-1}$. Membrane vesicles were purified from amorphous material by chromatography on a Sephadex G-200 column $(1.5 \mathrm{~cm} \times 30$ $\mathrm{cm})$ pre-equilibrated with buffer A. Membrane organelles that were not retained by the column were collected with the void volume. Fractions were examined for absorbance at $280 \mathrm{~nm}$ and endopeptidase activity as the marker enzyme for prostasomes (Ronquist et al., 1988) and then pooled and centrifuged at $105000 \mathrm{~g}$ for $120 \mathrm{~min}$. The pellet was suspended in buffer $\mathrm{A}$ and stored at $-196^{\circ} \mathrm{C}$ until use. Vesicle concentration was determined by Bio-Rad protein assay kit (Bradford, 1976) using BSA as standard protein.

\section{Enzyme activities}

Endopeptidase (EC 3.4.2.1) hydrolysing Succ(Ala) $)_{3}$-pNA was assayed according to Laurell et al. (1982). Dipeptidyl peptidase IV (EC 3.4.14.5) was assayed according to Nagatsu et al. (1976). Adenosine deaminase (EC 3.1.4.4) and 5' nucleotidase (EC 3.1.3.5) were assayed according to Franco $e t$ al. (1986). Protein concentration was determined by Bio-Rad protein assay kit (Bradford 1976) using BSA as standard protein. The cellular volume of spermatozoa was assumed to be $25 \mu \mathrm{m}^{3}$ by electron and confocal microscopy.

\section{Nucleoside and nucleotide determinations}

Washed sperm suspensions were incubated in $188 \mathrm{mmol}$ Hepes buffer $\mathrm{l}^{-1}$ containing $0.3 \mathrm{~mol}$ glucose $1^{-1}, 8.33 \mathrm{mmol}$ lactose $\mathrm{l}^{-1}$ and $50 \mathrm{U}$ penicillin $\mathrm{ml}^{-1}, \mathrm{pH} 7.5$ (buffer $\mathrm{B}$ ), at $37^{\circ} \mathrm{C}$ with shaking at 60 oscillations per min. At fixed intervals, aliquots containing $60-80 \times 10^{6}$ spermatozoa were withdrawn and extracted with $0.55 \mathrm{~mol}$ perchloric acid $\mathrm{l}^{-1}$. After $10 \mathrm{~min}$ on ice, the samples were centrifuged at $11000 \mathrm{~g}$ for $5 \mathrm{~min}$ and the supernatants were neutralized with equimolar addition of $\mathrm{K}_{2} \mathrm{CO}_{3}$.

Prostasome-like membrane vesicles were treated as described above. Nucleoside and nucleotide concentrations were determined by HPLC according to Stocchi et al. (1987) and Minelli et al. (1995).

\section{Sperm motility analysis}

Analyses of motility were performed using a computer assisted semen analyser (CASA, SCA 3.0, Microptic, Spain). The machine was equipped with a negative phase contrast optic system (Olympus $\mathrm{CH} 2$ ) and a Sony camera (Hyper HAD CCD/BN) connected to a Pentium $166 \mathrm{MHz}$. Images were analysed by sperm recognition algorithms considering sperm area and movements of each component of the sample. Equine sperm motility was assessed in 200 samples by determining total numbers of motile and static cells under appropriate experimental conditions. The method was validated with a linear model (SAS/STAT (1990) GLM,
REG,CORR procedure): $n=200$ real motile cells versus estimated, $r=0.92, P<0.001$.

\section{Electron microscopy}

Prostasome-like organelles and spermatozoa were fixed according to Ronquist et al. (1990). Ultrastructural examinations were carried out by Centro di Microscopia Elettronica, Università di Perugia, Italy.

\section{Statistical analysis}

The significance of variability between the mean value of the results obtained in the presence and absence of prostasome-like vesicles was determined by using Student's two-tailed (paired) $t$ test. Values were considered significant for $P<0.05$ and were expressed as mean \pm SEM.

\section{Results}

\section{Electron microscope observations}

The pellet mainly consisted of vesicles that were roughly round in shape with a diameter ranging from 75 to $175 \mathrm{~nm}$ (estimated average $100 \mathrm{~nm}$ ) as observed from sections at different levels. The particles were surrounded by a bilaminar unit membrane and contained an amorphous matrix (Fig. 1). These particles showed membrane-bound $5^{\prime}$ nucleosidase

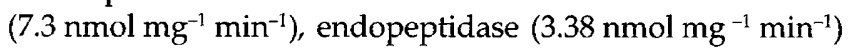
and dipeptidyl peptidase IV $\left(6.8 \mathrm{nmol} \mathrm{mg}^{-1} \mathrm{~min}^{-1}\right)$ activities.

\section{Nucleoside and nucleotide determinations}

The nucleoside and nucleotide concentrations of equine seminal prostasome-like vesicles were determined (Fig. 2). Only adenosine and its tri- and diphosphate derivatives were detected in the vesicles. AMP as well as other nonadenylic nucleotides were absent.

Nucleoside and nucleotide concentrations of equine spermatozoa kept in buffer $\mathrm{B}$ at $37^{\circ} \mathrm{C}$ for $120 \mathrm{~min}$ in the presence and absence of seminal plasma vesicles were also determined (Fig. 3). Total degradation of ATP accompanied by the appearance of its degradative products, that is, ADP, AMP and adenosine, was observed in equine spermatozoa kept in glucose-lactose medium without the seminal plasma vesicles. In the presence of the vesicles, the intracellular ATP concentration remained high and AMP did not accumulate. Consequently, the energy charge of the cell was stabilized at vital physiological values by these prostasome-like vesicles, which is in contrast to the situation observed with spermatozoa alone. After $60 \mathrm{~min}$ of incubation in buffer B, the energy charge values, ranging between 0.5 and 0.4 , were indicative of the deficient vitality of the cells. In these conditions, spermatozoa were almost totally immotile, whereas the same cells kept in the presence of the vesicles 

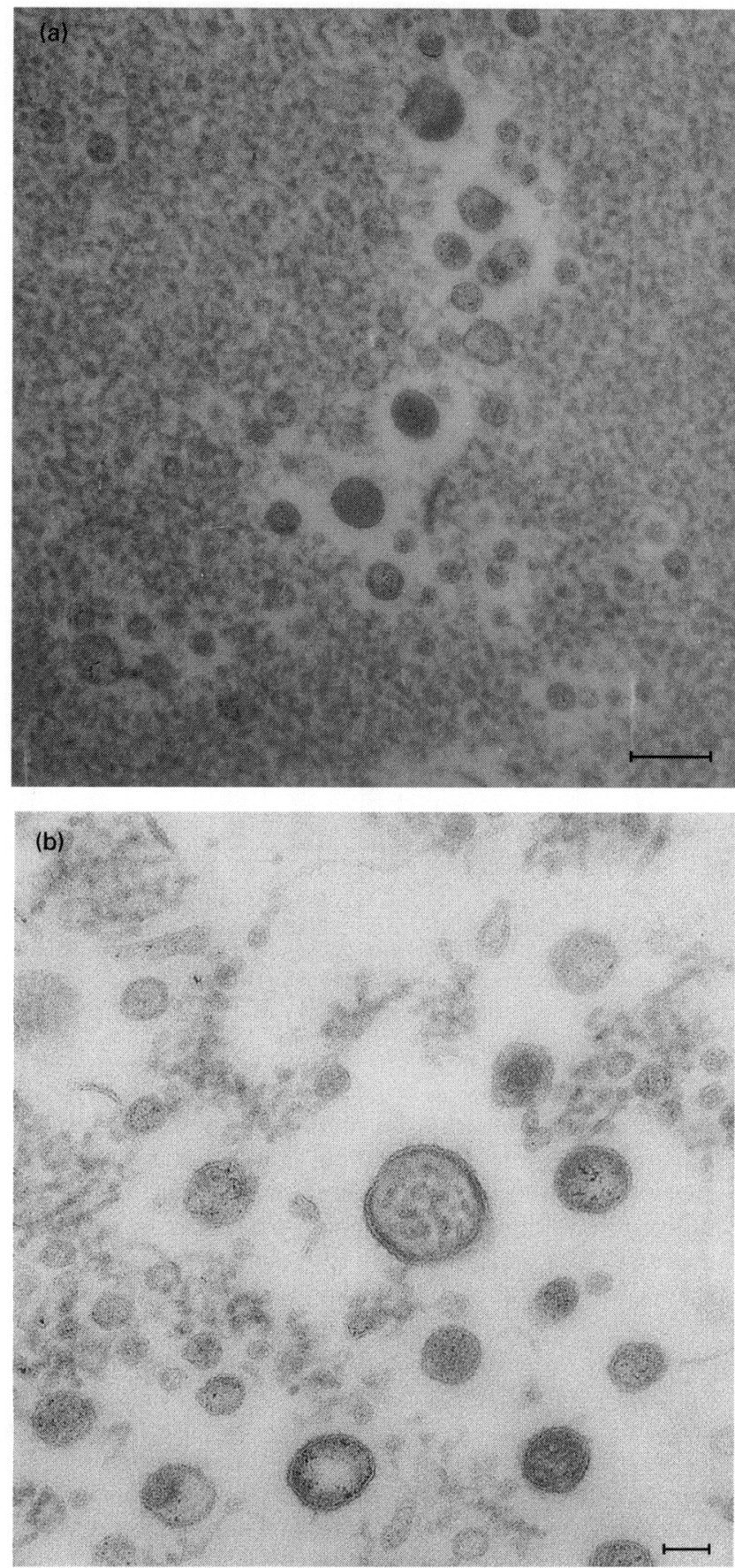

Fig. 1. Transmission electron micrograph of equine seminal plasma membrane vesicles (a) before and (b) after gel filtration on Sephadex $\mathrm{G} 200$. Scale bars represent $100 \mathrm{~nm}$.

were as motile after $60 \mathrm{~min}$ as at the beginning of the experiment (sperm motility analysis by the CASA system).

\section{Interaction of equine spermatozoa with seminal prostasome- like vesicles}

The suspension of washed spermatozoa was mixed with purified vesicles and incubated at $37^{\circ} \mathrm{C}$ for $120 \mathrm{~min}$. These

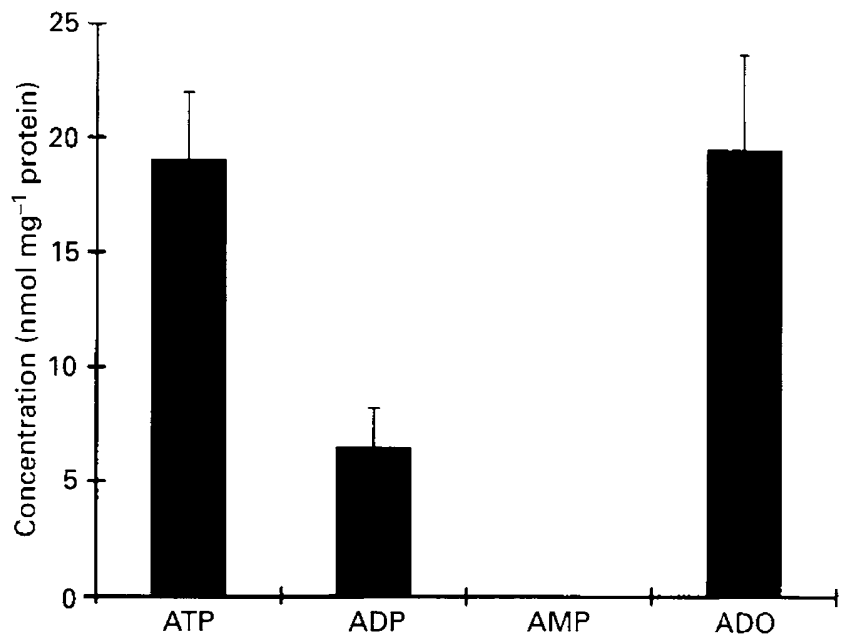

Fig. 2. Concentration of adenylic nucleotides and nucleosides of equine prostasome-like seminal plasma vesicles as determined by HPLC. Values are the means \pm SEM, $n=20$. ATP, adenosine triphosphate; ADP, adenosine diphosphate; AMP, adenosine monophosphate; $\mathrm{ADO}$, adenosine.

preparations were observed under the electron microscope. At time 0 (the time of addition of the vesicles), the washed spermatozoa were organelle-free (Fig. 4a), indicating that the fusion-like process is time dependent. After $15 \mathrm{~min}$ incubation, the start of the fusion-like process was observed as the formation of a bridge between the membranes (Fig. $4 b$ ) and after $30 \mathrm{~min}$ complete mixing of the membranes was apparent (Fig. 4c).

Endopeptidase assays were carried out with washed spermatozoa at several time intervals (Fig. 5). These results show that this enzyme, which is used as a prostasome marker (Ronquist and Brody, 1985), is not normally present on surface of spermatozoa. After the addition of the prostasome-like vesicles, equine spermatozoa displayed endopeptidase activity, which increased up to $60 \mathrm{~min}$, supporting the suggestion of a stable interaction between the organelles and the cells of $30-35 \%$.

The percentage of prostasome-like vesicles undergoing a fusion-like process with spermatozoa, that is, the percentage of enzyme activity transferred to the sperm cells, as calculated from the endopeptidase assays, was $30-35 \%$. This finding was supported by electron microscopic observations.

\section{Discussion}

It has been known for a long time that the seminal plasma of several mammals contains membrane particles. Therefore, the occurrence of membrane vesicles in equine seminal plasma was not unexpected.

In man, these particulate elements are derived from the prostate by exocytosis and diacytosis and are named prostasomes (Brody et al., 1983). In bovine seminal plasma, the organelles originate from seminal vesicles and are appropriately referred to as vesiculosomes. The seminal vesicles in different species differ not only in their site of 

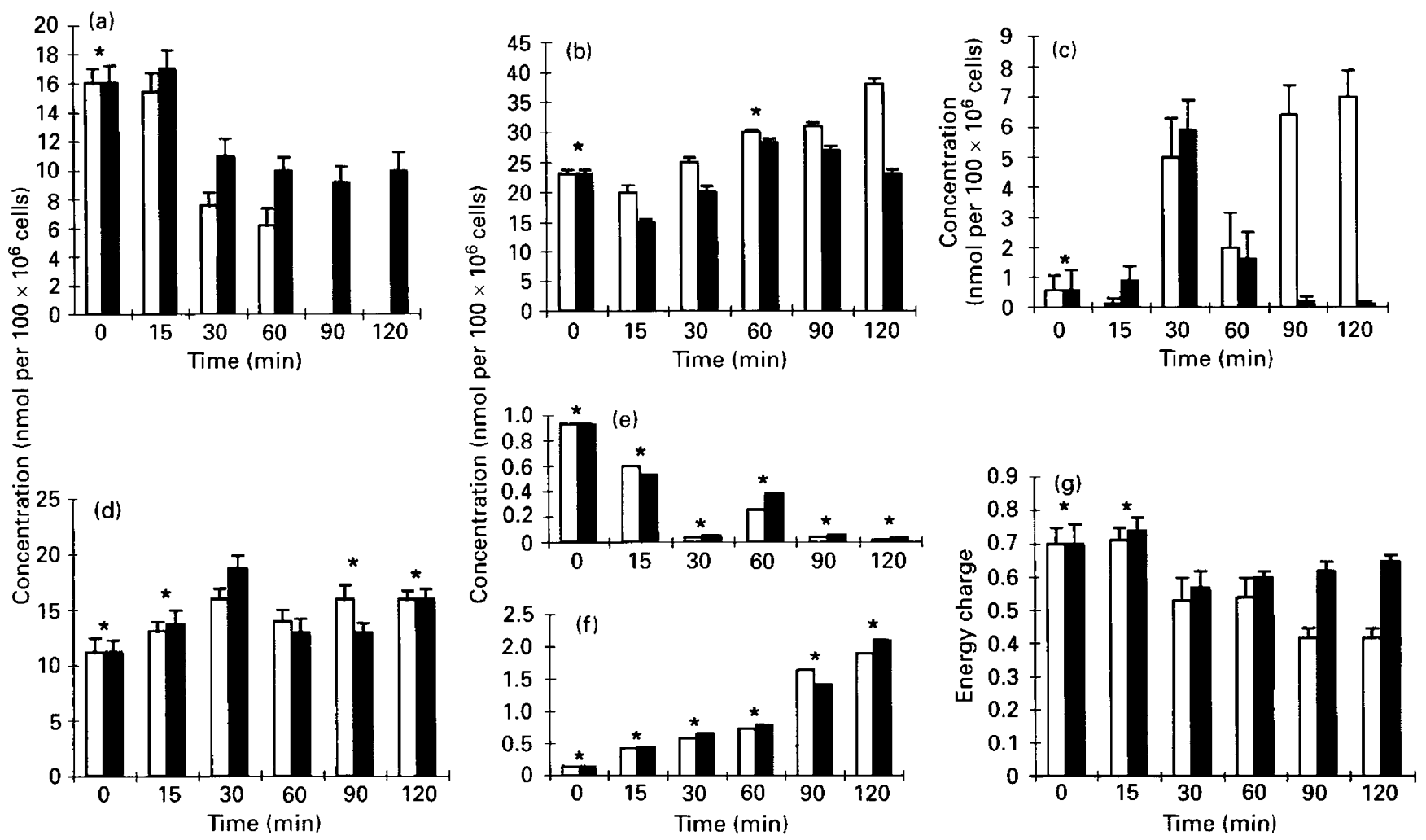

Fig. 3. Energy charge and nucleoside and nucleotide concentration of equine spermatozoa in the absence ( $\square$ ) and in the presence ( $\square$ ) of prostasome-like seminal plasma vesicles as determined by HPLC. Values are the means $\pm \mathrm{SEM}, n=15$. Asterisks denote values are not significantly different at $P>0.05$. (a) adenosine triphosphate, (b) adenosine diphosphate, (c) adenosine monophosphate, (d) adenosine, (e) inosine monophosphate, $(f)$ inosine and $(g)$ energy charge.

origin but also in their biochemical composition. Bovine vesiculosomes contain aminopeptidase A (Agrawal and Vanha-Pertulla, 1985) and alanyl-aminopeptidase (Agrawal and Vanha-Pertulla, 1986a,b). In addition, the particles show $\mathrm{Mg}-\mathrm{Ca}$ ATPase, $\gamma$-glutamyl transpeptidase and dipeptidyl peptidase IV activities, which are all well known membranebound enzymes in cells and tissues (Agrawal and VanhaPertulla, 1987). However, the endopeptidase active on Succ(Ala) ${ }_{3}$-pNA is not present in bovine vesiculosomes, whereas it characterizes human prostasomes (Laurell et al., 1982; Krassnig et al., 1985).

The vesicles identified in equine seminal plasma in this study present nucleotidic components (Ronquist and Frithz, 1986) and enzyme activities similar to those found in human prostasomes (Laurell et al., 1982; Fabiani and Ronquist, 1993; De Mester $e t$ al., 1996). Moreover, there is a strong anatomical resemblance between human and equine genito-urinary tracts. Thus, there is a strong possibility that these equine particles may be of prostatic origin. However, further investigations are required to confirm their anatomic derivation.

Rabbit seminal vesicles have been shown to block fertilization (Davis and Hungund, 1976). In contrast, prostasomes promote forward motility (Ronquist and Brody, 1985) and vesiculosomes stimulate motility and the normal acrosome reaction (Agrawal and Vanha-Pertulla, 1987). Motility-promoting activity by prostasomes requires membrane integrity. Therefore, this effect is not due to the protein composition of the vesicles (Stegmayr and Ronquist, 1982).

It has been hypothesized that prostasomes may assist the fertilizing potential of spermatozoa by adhering to them (Ronquist et al., 1990) and modifying their microenvironment. In the present study, before the computerized analysis of the effects of these prostasome-like vesicles on the motility of equine spermatozoa was undertaken, the occurrence of this interaction was investigated by electron microscopy and biochemical studies. Under the electron microscope the interaction between the sperm cells and the vesicles appeared to be a fusion-like process. This event starts with the formation of a clearly visible bridge between the membranes and then gradually proceeds until the vesicle is completely embedded in the sperm cell membrane. A similar process occurs between human spermatozoa and prostasomes, although fusion was not demonstrated (Ronquist et al., 1990). Arienti et

Fig. 4. Scanning electron micrographs of equine spermatozoa incubated in the presence of prostasome-like seminal vesicles for (a) 0 (b) 15 and (c) $30 \mathrm{~min}$. Arrows indicate (b) the bridge between the sperm and vesicle membranes, and (c) the vesicle completely embedded in the sperm membrane. Scale bars represent $1 \mu \mathrm{m}$. 

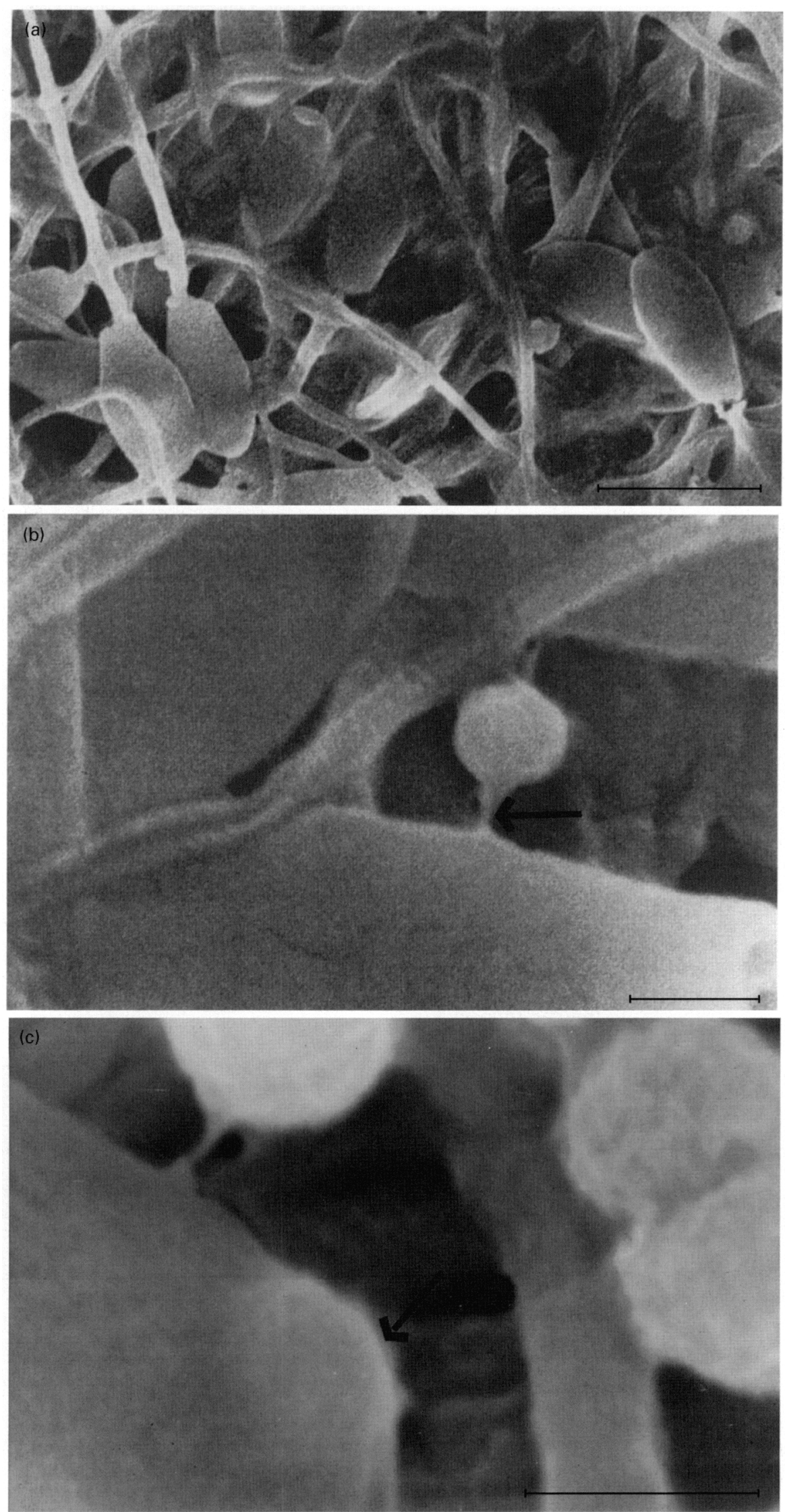

Fig. 4. 


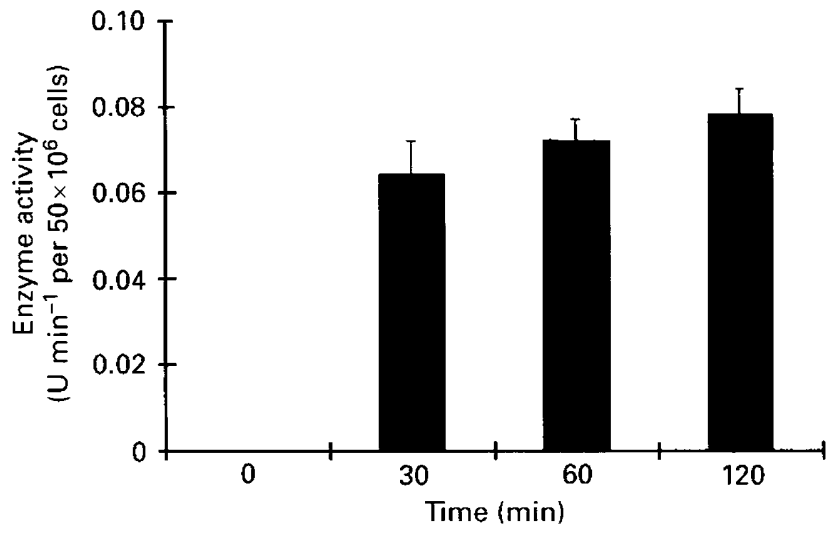

Fig. 5. Endopeptidase activity on equine spermatozoa $\left(200 \times 10^{6}\right)$ incubated in the presence of seminal plasma vesicles. At fixed intervals, aliquots of $50 \times 10^{6}$ cells were withdrawn and assayed for enzyme activity at $410 \mathrm{~nm}$.

al. (1997) reported fusion between human prostasomes and spermatozoa in acidic conditions $(\mathrm{pH} 4-5)$. This $\mathrm{pH}-$ dependent fusion required at least one protein on the sperm surface, but proteins on the prostasomal surface also appeared to be important. Several methods, namely the release of octadecyl-rhodamine $G$ fluorescence selfquenching, fluorescence microscopy and flow cytometry, were used to investigate the fusion process in the study of Arienti et al. (1997). However, the ultrastructural results from the present study showed the interaction between equine spermatozoa and prostasome-like vesicles occurred at $\mathrm{pH} 7.5$, which is in contrast to human spermatozoa and prostasomes.

The presence of endopeptidase activity on the membrane of washed spermatozoa that had previously been incubated with the prostasome-like vesicles supports the proposed interaction between the two membranes. This enzyme activity, which is a marker of the equine seminal vesicles, is not normally present on the sperm cells. The equine spermatozoa acquire the enzyme by the fusion-like process with the added vesicles. Furthermore, the variation in the nucleoside and nucleotide concentration of the sperm cells upon the addition of the membrane vesicle preparation indicates that the nucleotidic and nucleosidic content of the vesicles is incorporated into the cells, thus stabilizing their energy charge. This fusion-like process may also result in the acquisition of new properties by the sperm cells. Therefore, the fusion process may take part in the activation and viability of the spermatozoa, especially as they enter the female genital tract.

The authors are grateful to Mary Kerrigan for linguistic suggestions.

\section{References}

Agrawal $\mathbf{Y}$ and Vanha-Pertulla $\mathbf{T}$ (1985) Variable distribution of aminopeptidase $\mathrm{A}$ in male reproductive organs of mammals International Journal of Andrology 8 243-256

Agrawal Y and Vanha-Pertulla T (1986a) Studies on the multiple forms of aminopeptidase $A$ in bovine seminal vesicles secretion International Journal of Biochemistry $18465-471$
Agrawal Y and Vanha-Pertulla T (1986b) Alanyl aminopeptidase of bovine seminal vesicle secretion International Journal of Biochemistry 18 725-729

Agrawal Y and Vanha-Pertulla T (1987) Effect of secretory particles in bovine seminal vesicle secretion on sperm mobility and acrosome reaction foumal of Reproduction and Fertility $79409-419$

Arienti G, Carlini E and Palmerini CA (1987) Fusion of human spermatozoa to prostasomes at acidic $\mathrm{pH}$ journal of Membrane Biology $15589-94$

Bradford MM (1976) A rapid and sensitive method for the quantitation of microgram quantities of protein utilizing the principle of protein dye binding Analytical Biochemistry 72 248-254

Breitbart A and Rubinstein S (1982) Characterization of $\mathrm{Mg}^{2+}$ and $\mathrm{Ca}^{2+}$ ATPase activity in membrane vesicles from ejaculated ram seminal plasma Archives of Andrology 9 147-157

Brody I, Ronquist G and Gottfries A (1983) Ultrastructural localization of the prostasome - an organelle in human seminal plasma Upsala Journal of Medical Sciences 88 63-80

Davis BK (1973) Occurrence of vesicles in rabbit seminal plasma Experientia 29 1484-1487

Davis BK and Hungund BJ (1976) Effect of modified membrane vesicles from seminal plasma on the fertilizing capacity of rabbit spermatozoa Biochemical and Biophysics Research Communications 69 1004-1010

De Mester I, Vanhoof G, Lambeir AM and Scharpe S (1996) Use of immobilized adenosine deaminase for the rapid purification of native human CD26/dipeptidyl-peptidase IV Journal of Immunological Methods 189 99-105

Fabiani $\mathbf{R}$ and Ronquist G (1993) Characteristics of membrane-bound 5 'nucleotidase on human prostasomes Clinica Chimica Acta 216 175-182

Fornes MW, Barbieri A, Sosa MA and Bertini F (1991) First observations on enzymatic activity and protein content of vesicles separated from rat epididymal fluid Andrologia 23 347-351

Franco R, Canella EI and Bozal J (1986) Heterogeneous localization of some purine enzymes in subcellular fractions of rat brain and cerebellum Neurochemical Research $11423-435$

Keiding R, Horder H, Gerhardt W, Pitkanen E, Tenhunen R, Stromme JH, Theodorsen L, Waldenstrom J, Tryding $\mathbf{N}$ and Westlund $\mathbf{L}$ (1974) Recommended methods for the determination of four enzymes in blood Scandinavian journal of Clinical Laboratory Investigations 33 291-306

Kelly RW (1991) Seminal plasma immunosuppressive activity: the Achilles heel of reproduction International Journal of Andrology 14 243-247

Krassnigg F, Engl R, Topfer-Petersen E, Friess $\mathbf{R}$ and Schill WB (1985) Characterization of angiotensin converting enzyme in human seminal plasma. In Protides of the Biological Fluids Vol. 32 pp 285-288 Ed. H Peeters. Pergamon Press, Oxford

Laurell CB, Weiber H, Ohlsson K and Rannevik G (1982) A Zn-dependent peptidase in prostatic organelles present in seminal plasma Clinica Chimica Acta 126 161-170

Lord EM, Sensabaugh GF and Stites DP (1977) Immunosuppressive activity of human seminal plasma Journal of Immunology 118 1704-1711

Minelli A, Miscetti P, Proietti A, Luzi L and Mezzasoma I (1995) Adenosine triphosphate catabolism in bovine spermatozoa Comparative Biochemistry and Physiology 110B 605-611

Minelli A, Allegrucci C and Mezzasoma I (1997a) 3H-R-N6phenylisopropyladenosine agonist binding to the solubilized A1 adenosine receptor from bovine epidydimal spermatozoa Archives of Biochemistry and Biophysics $33754-61$

Minelli A, Moroni M, Trinari D and Mezzasoma I (1997b) Hydrolysis of extracellular adenine nucleotides by equine epidydimal spermatozoa Comparative Biochemistry and Physiology 117B 531-534

Nagatsu T, Hino $M$, Fuyamada $H$, Hayakawa $T$, Sakakibara $S$, Nakagawa $Y$ and Takemoto $T$ (1976) New chromogenic substrate for X-prolyl dipeptidyl-aminopeptidase Analytical Biochemistry 74 466-476

Ronquist G and Brody I (1985) The prostasome: its secretion and function in man Biochimica and Biophysica Acta 822 203-218

Ronquist $\mathrm{G}$ and Frithz G (1986) Prostasomes in human semen contain ADP and GDP Acta Europaea Fertilitatis 17 273-276

Ronquist G, Brody I, Gottfries A and Stegmayr B (1978a) An $\mathrm{Mg}^{2+}$ and $\mathrm{Ca}^{2+}$ stimulated adenosine triphosphatase in human prostatic fluid. Part I Andrologia 10261-272

Ronquist G, Brody I, Gottfries A and Stegmayr B (1978b) $\mathrm{An} \mathrm{Mg}^{2+}$ and $\mathrm{Ca}^{2+}$ stimulated adenosine triphosphatase in human prostatic fluid. Part II Andrologia $10427-433$

Ronquist G, Frith G and Jansson A (1988) Prostasome membrane - associated enzyme activities and semen parameters in men attending an infertility clinic Urology International 43 133-198 
Ronquist G, Nilsson BO and Hejrten S (1990) Interaction between prostasomes and spermatozoa from human semen Archives of Andrology 24 $147-157$

Stegmayr B and Ronquist G (1982) Stimulation of sperm progressive mobility by organelles in human seminal plasma Scandinavian Journal of Urology and Nephrology 16 85-90
Stocchi V, Cucchiarini C, Canestrari F, Piacentini MP and Fornaini G (1987) A very fast ion-pair reversed-phase HPLC method for the separation of the most significant nucleotides and their degradation products in human red blood cells Analytical Biochemistry 167 181-190 